\title{
Implementasi Lorawan Server Untuk Sistem Tracking Perahu Nelayan Berbasis MQTT Protocol
}

\author{
Willy Permana Putra ${ }^{1}$, Rizal Iman $\mathbf{M}^{2}$, A Sumarudin ${ }^{3}$, Agfianto Eko Putro \\ ${ }_{1,2,3}$ Teknik Informatika, Politeknik Negeri Indramayu \\ ${ }^{4}$ Jurusan Ilmu Komputer, Universitas Gadja Mada \\ willy@polindra.ac.id ${ }^{1}$,shumaru@polindra.ac.id ${ }^{2}$,agfi@ugm.ac.id ${ }^{4}$
}

\begin{tabular}{l}
\hline Article Info \\
\hline Article history: \\
Received : 08-11-2018 \\
Revised : 27-11-2018 \\
Accepted : 05-12-2018 \\
\hline
\end{tabular}

Keyword:

Tracking, nelayan, lorawan, server, $M Q T T$.

\begin{abstract}
Luas perairan Indonesia sebesar $64.97 \%$ dari luas wilayah Indonesia dengan jumlah nelayan sebanyak 2.17 juta nelayan di seluruh Indonesia. Kebanyakan dari nelayan Indonesia tersebut masih menggunakan cara tradisional dalam melaut. Dalam penelitian ini dilakukan untuk dapat membuat server sistem tracking perahu nelayan secara realtime. Dengan sistem ini, nelayan kecil dengan kegiatan nya hanya $1-2$ hari melaut (one day fishing) dalam melakukan pelayarannya tingkat keselamatan nelayan dapat ditingkatkan dikarenakan dapat terpantau posisinya. Sistem yang dikembangkan menggunakan server berbasis mqtt protocol di sisi gateway. Server menggunakan mysql server menggunakan get JSON Parsing. Sebagai front end sistem tracking untuk menampilkan kordinat perahu berbasis web. Dari hasil implementasi didapat bahwa server dapat merespon dengan baik dari end device dengan melakukan pengiriman data secara periodik.
\end{abstract}

Copyright (C) 2018 Journal of Applied Informatics and Computing. All rights reserved.

\section{Pendahuluan}

Program pemerintah peningkatan sector ekonomi maritime didasarkan akan luas wilayah Indonesia dan potensi perikanan terbesar di dunia. Presiden pada sidang terbatas kabinet kerja pada bulan Juni tahun 2016 mengatakan "70 persen dua per tiga luas wilayah Indonesia adalah lautan. Potensinya sangat besar untuk menjadi penggerak perekonomian nasional. Masalahnya, hingga saat ini potensi tersebut belum bisa dimanfaatkan secara maksimal oleh masyarakat". Hal ini didasarkan pada luas indonesia yang memiliki wilayah laut sebesar $64,97 \%$ dari total wilayah Indonesia. Menurut data BPS 2003 - 2013 nelayan turun dari 1,7 juta jiwa menjadi 64 ribu jiwa. Factor turunnya minat penduduk pesisir pantai menjadi nelayan adalah kurang menguntukannya berprofesi sebagai nelayan.

Dengan demikian untuk menjawab permasalahan nelayan diatas, adalah penerapan teknologi yang dapat meningkatkan hasil tangkap ikan laut dan aktifitas pergerakan nelayan dapat di lihat dan di pantau keberadaanya jika sewaktu-waktu terjadi masalah. Salah satu teknologi yang dapat digunakan yaitu adalah dengan cara sistem tracking perahu nelayan secara realtime. Dengan adanya sistem ini diharapkan nelayan kecil dapat dipantau keberadaannya. Dengan adanya sistem ini pula nelayan dapat mengetahui betul posisi dimana nelayan itu berada dan bisa berkomunikasi dengan nelayan disekitarnya. Tujuan dari penelitian ini adalah memanfaatkan teknologi yang tepat guna bagi si nelayan sehingga nelayan dapat dipantau posisi dan keberadaannya.

Teknologi yang dipergunakan di dalam penelitian ini menggunakan MQTT (Message Queue Telemetry Transport) merupakan protokol komunikasi yang sangat sederhana dan ringan dengan metode machine to machine (M2M). MQTT dirancang untuk perangkat yang memiliki keterbatasan dengan bandwidth rendah. MQTT bersifat lightweight message artinya MQTT berkomunikasi dengan mengirimkan data pesan yang memiliki header berukuran kecil yaitu hanya sebesar 2bytes untuk setiap jenis data. Prinsip dari MQTT adalah untuk meminimalkan bandwidth serta memberikan jaminan pengiriman data walapun koneksi tidak stabil.

Penerapan MQTT telah lama sejak 1999 secara luas di berbagai industri. Publish/subscribe sendiri adalah sebuah pola pertukaran pesan di dalam komunikasi jaringan dimana pengirim data disebut publisher dan penerima data disebut dengan subscriber, metode publish/subscribe memiliki beberapa kelebihan salah satunya yaitu loose coupling atau decouple dimana berarti antara publisher dan subscriber tidak saling mengetahui keberadaannya, terdapat 3 buah 
decoupling yaitu time decoupling, space decoupling dan synchronization decoupling, time decoupling adalah sebuah kondisi dimana publisher dan subscriber tidak harus saling aktif pada waktu yang sama, space decoupling adalah dimana publisher dan subscriber aktif di waktu yang sama akan tetepi antara publisher dan subscriber tidak saling mengetahui keberadaan dan identitas satu sama lain, dan yang terakhir adalah synchronization decoupling kondisi dimana pengaturan event baik itu penerimaan atau pengiriman pesan di sebuah node hingga tidak saling mengganggu satu sama lain [6]. Mosquitto Broker adalah salah satu opensource broker pesan yang mengimplementasikan protokol MQTT versi 3.1 dan 3.1.1, broker mosquitto juga mendukung implementasi server lightweight dari MQTT maupun MQTT$\mathrm{SN}$, mosquitto broker ditulis dalam bahasa pemrogram $\mathrm{C}$ dengan alasan agar dapat tetap bekerja pada mesin yang tidak mendukung JVM, dari hasil pengujian yang telah dilakukan sebelumnya broker mosquitto dapat mendukung 100.000 koneksi secara bersamaan [10]. Untuk server lorawan sendiri menggunakan thingspeak yang merupakan cloud data platform (https://thingspeak.com). Dari cloud data platform ini kita pergunakan untuk membuat lorawan server untuk implementasi dari server lora data. Dengan thingspeak dapat memperoleh API call [12] dari API thingspeak menggunakan API read untuk mengambil data untuk disimpan di server sistem tracking perahu yang akan dikembangkan. Dalam artikel ini, akan dibahas sistem server lorawan untuk implementasi tracking perahu.

\section{Metode Penelitian}

Seperti dipaparkan di atas, penelitian ini membahas tentang sistem server pada lorawan menggunakan MQTT protokol yang digunakan. Sistem yan dibangun menggunakan lora sistem dari perahu dan dikirim menggunakan lora protokol untuk transport data dari perahu ke gateway. Di gateway, disini menggunakan protokol MQTT untuk mengirimkan data ke thingspeak.

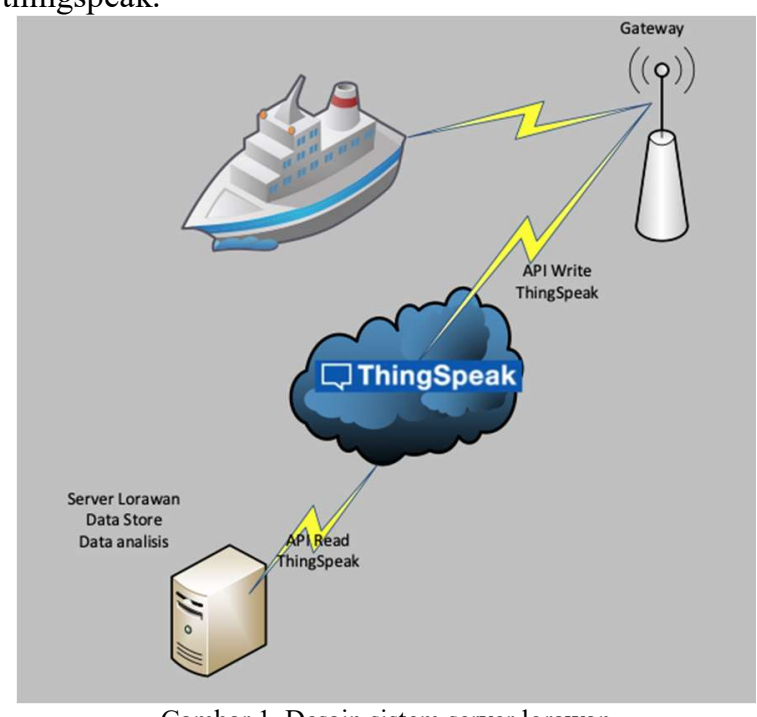

Gambar 1. Desain sistem server lorawan
Berikut adalah langkah penelitian yang kita rencanakan

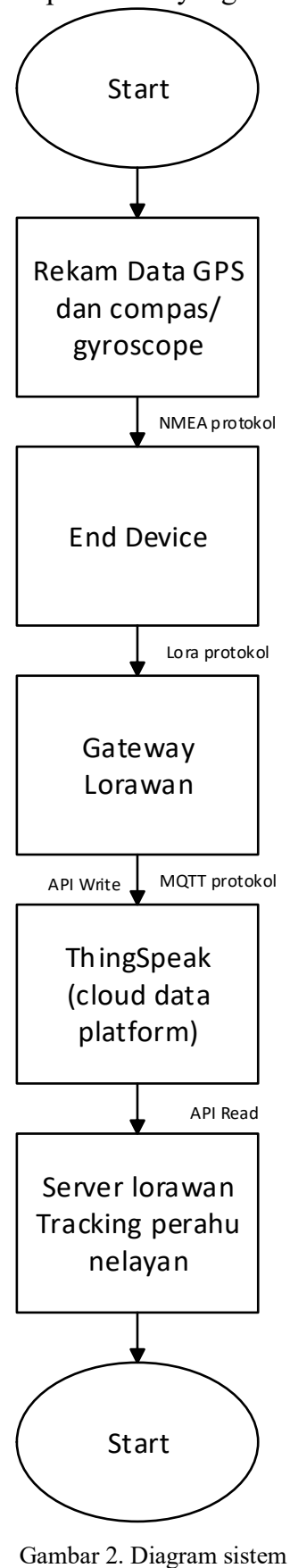

Desain channel thingspeak menggunakan 2 field dengan menentukan terlebih dahulu beberapa setting data: 
TABEL I

FORMAT DATA CHANNEL KONFIGURASI

\begin{tabular}{|l|l|}
\hline Id Channel & Channel id perangkat \\
\hline Name & Nama data \\
\hline description & Deskripsi channel \\
\hline Latitude device & Latitude device gateway \\
\hline Longitude device & Logitude device \\
\hline Field 1 & Lat/log end device (perahu) \\
\hline Field 2 & Roll/pitch/compas (end device perahu) \\
\hline Created at & Tanggal pembuatan channel \\
\hline Update at & Tanggal update terakhir device \\
\hline Last entry id & Data masuk terakhir \\
\hline
\end{tabular}

Format data feeds, adalah sebagai berikut:

TABEL II

FORMAT DATA FEEDS DARI DATA SENSORI

\begin{tabular}{|l|l|l|l|}
\hline Created at & Entry ID & Field 1 & Field 2 \\
\hline Data di & ID data & Latitude/ & Roll/ pitch/ \\
buat/diteri & masuk & longitude & compas (perahu) \\
ma & (berupa & (perahu) data & data yang \\
& urutan data) & yang diterima & diterima \\
& & & \\
\hline
\end{tabular}

Data ini akan di get menggunakan JSON untuk melakukan parsing data dari thing speak ke dalam sistem server. Back end menggunakan laravel sistem dengan database mySql.

\section{Hasil Dan Pembahasan}

Device yang dipergunakan dari sistem tracking ini adalah sebagai berikut.

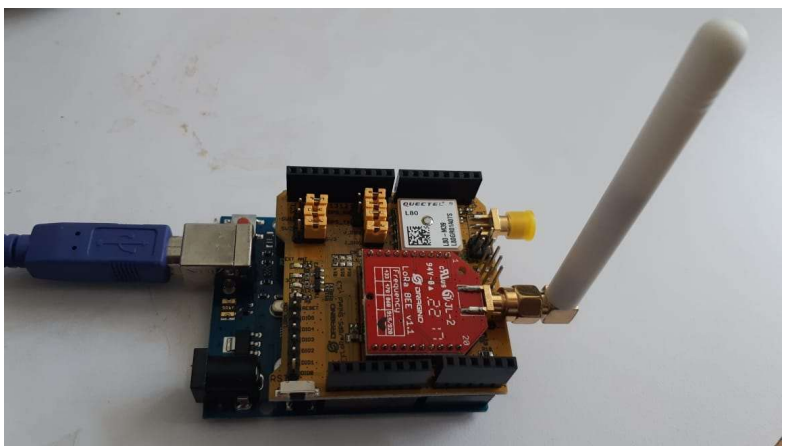

Gambar 3. End Device

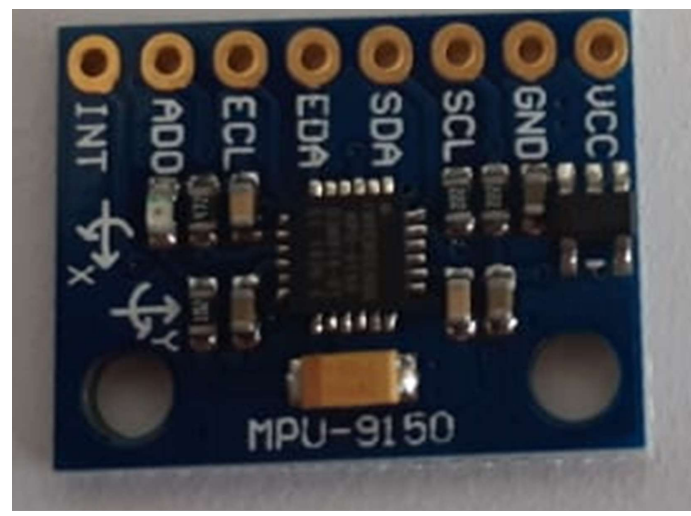

Gambar 4. Gyroscope sensor MPU-9150

Dari data sensor ini, diambil data kordianat gps dengan mendapatkan nilai kordinat latitude dan longitude. Sedangkat arah/course dari perahu didapat dari sensor MPU-9150. Data yang disimpan dikirimkan ke gateway melalui lora protokol. Berikut data dari yang didapatkan dari end device sistem tracking.

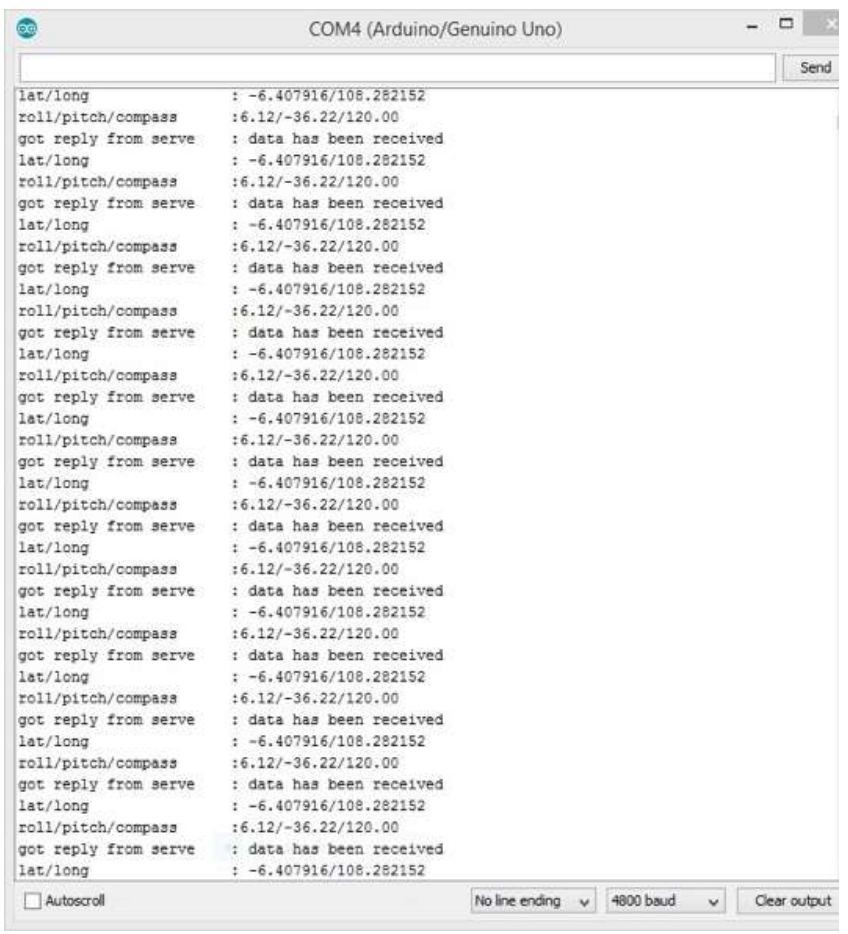

Gambar 5. Data Sensor dari End Device di Gateway

Dari data ini, akan dikirimkan ke server dengan menggunakan library thingspeak berikut:

ThingSpeak.setField(2,gyro);

ThingSpeak.setField(1,gps);

ThingSpeak.writeFields(myChannelNumber, myWriteAPIKey);

Yang dibutuhkan dalam proses pengiriman ini adalah jenis format data dari data sensor. Dalam proses pengiriman 
menggunakan stream char maka perlu dilakukan perubahan type data dari double float kedalam char. Dalam implementasi sistem ini menggunakan teknik stream untuk setiap sensor dengan hanya menggunakan satu field dan di batasi dengan “"” untuk membatu dalam proses parsing data di server.

\section{lora_gateway_outdoor Status - Sensor - System - Natnork -}

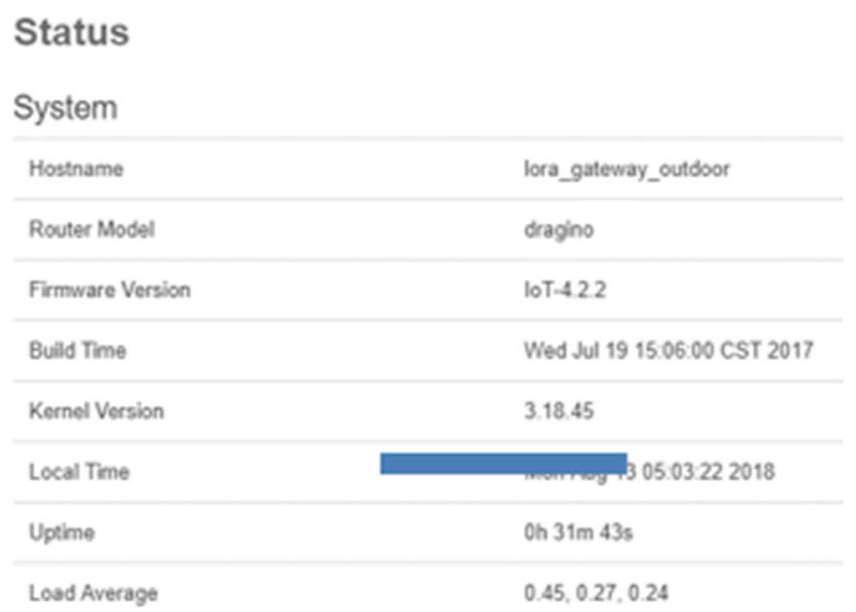

Gambar 6. Lora Gateway

Gateway ini menggunakan dragino lora gateway dengan frekuensi 915 Mhz. Dari gateway ini koneksi dengan internet untuk mengirim data ke data cloud platform menggunakan wifi koneksi. Berikut settting lorawan setting untuk gateway.

\section{lora_gateway_outdoor Status- Sensor - System - Not}

\section{Select loT Server \\ Select the loT Server type to connect}

\section{Select loT Server}

IOT Server MATT Server
Debugger $\square \square$ TTN Packet Forwarder Debugger

\section{Save \& Apply Save Reset}

Gambar 7. Iot Server Setting

Berikut hasil pengiriman data dari gateway ke thingspeak.com.

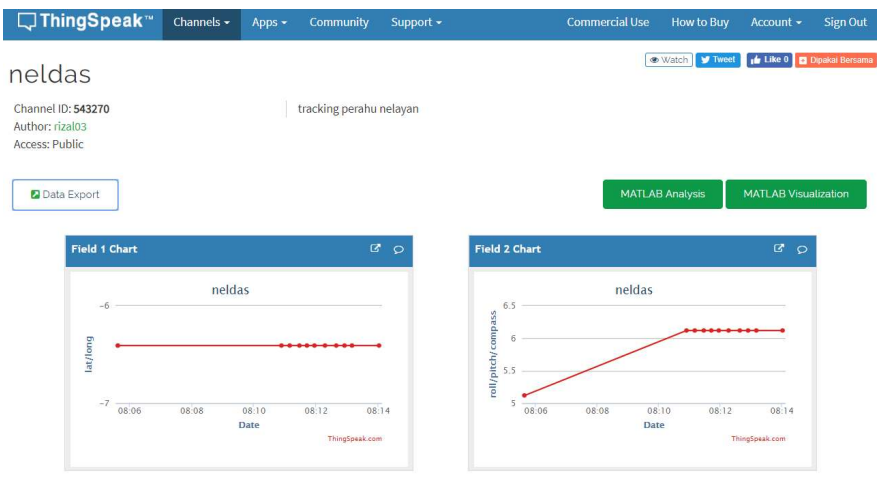

Gambar 8. Data Cloud Platform

Dari thingspeak ini yang dikirim dari gateway menggunakan protokol mqqt dengan format sebagai berikut:

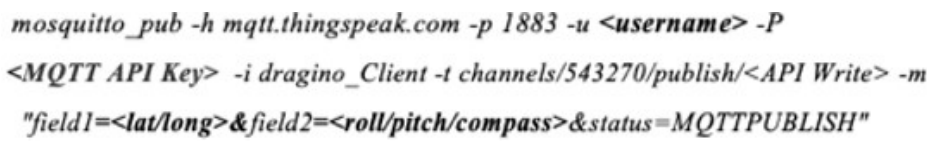

Username di ambi nama author di channel yang dibangun, MQTT API key dari aplikasi thingspeak profile.

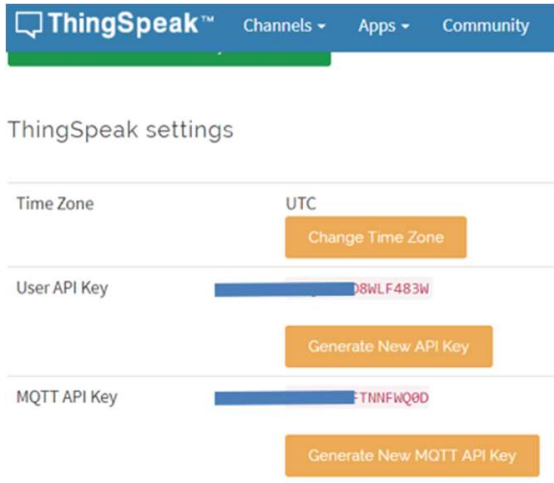

Gambar 9.MQTT API Key

Dari setiap data yang di simpan di dalam akan dilakukan feed JSON dengan melakukan parsing menggunakan entry_id yang terakhir/terbesar yang akan di simpan didalam server. Berikut hasil dari export xml format dari thingspeak yang diambil.

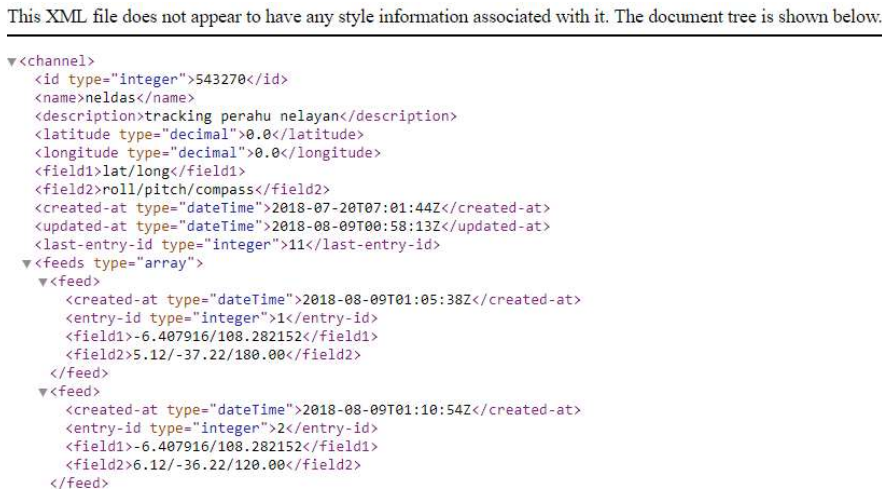

Gambar 10. XML File Data Entry Thingspeak 
Dari data tersebut maka dilakukan get data dari thingSpeak ke server dengan menggunakan JSON format API menggunakan API read dari thingSpeak. https://api.thingspeak.com/channels/<xxxxxx $>$ /feeds.json?ap i_key $=<$ APIread $>$ untuk melakukan get data dari server.

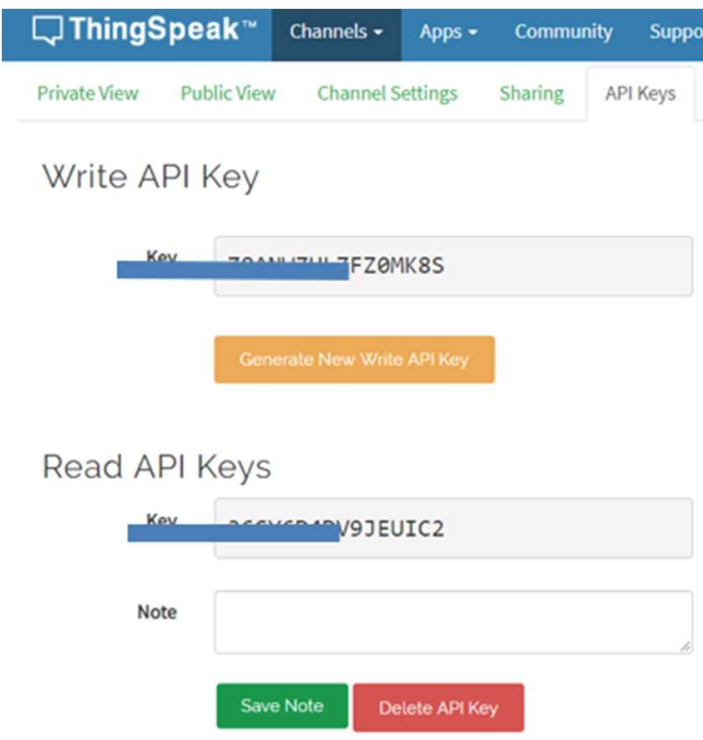

Gambar 11. Write dan read API

Data tersebut kemudian di parsing, dilakukan simpan data kedalam data server system tracking yang dibangun menggunakan MySQL. Data tracking di tampilkan dalam map yang menggunakan map API google.

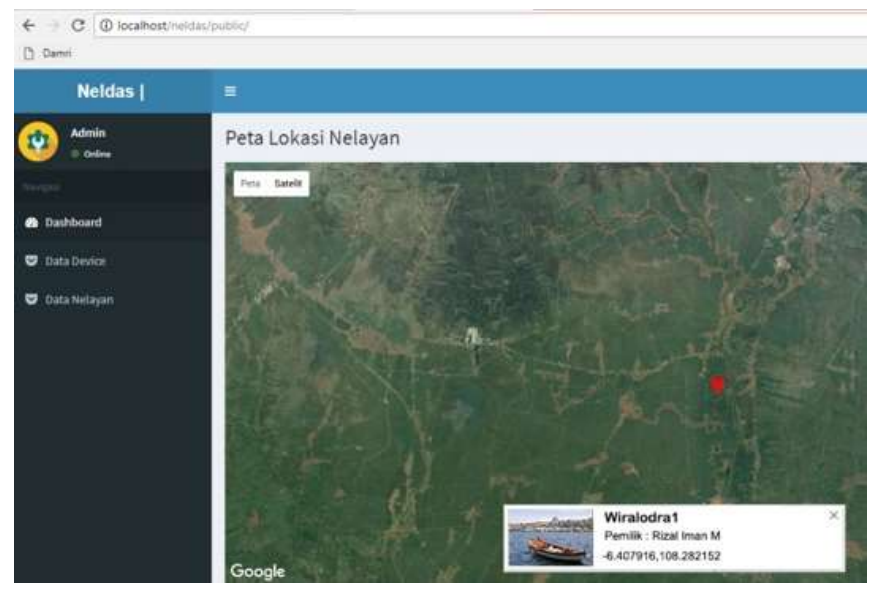

Gambar 12. Peta Tracking Perahu

\section{KESIMPULAN}

Dari hasil implementasi diatas, penelitian LoraWAN server menggunakan MQTT Protokol untuk implementasi tracking perahu nelayan dapat di implementasikan. Dengan menggunakan protocol ini, system tracking bias lebih sederhana dan menggunakan infrastruktur yang memungkinkan di laut dengan system RF berbasis LoraWAN. Server dapat menerima data menggunakan middleware data cloud platform, yang kemudian di get menggunakan JSON parsing.

Dalam penelitian ini, belum dibahas tentang jarak maksimum perahu yang dapat di traking dan delay, error rate dan bandwith maksimum dari system. Penelitian akan dilanjutkan dengan memperhatikan variable-variable diatas.

\section{UCAPAN TERIMA KASIH}

Terimakasih untuk semua pihak baik itu kampus tercinta yaitu Politeknik Negeri Indramayu atau yang lain yang tidak saya sebutkan satu persatu.

\section{DAFTAR PUSTAKA}

[1] Kementrian Sekretariat Negara Republik Indonesia, "Geografi Indonesia," $2017 . \quad$ [Online]. Available: http://indonesia.go.id/?page_id=479. [Accessed 15 June 2017].

[2] Wisnubro, "Jaringan Pemberitaan Pemerintah (JPP)," 2017. [Online]. Available: https://jpp.go.id/humaniora/sosial-budaya/301315-kkpakan-mendaftarkan-14-572-pulau-ke-pbb. [Accessed 15 June 2017].

[3] J. Hartriani, "Katadata News and Research," 2017. [Online]. Available: http://katadata.co.id/infografik/2017/02/13/potensi-besarlaut-indonesia. [Accessed 16 June 2017].

[4] United Nations Development Programme, "8 facts about Indonesia's ocean," $2017 . \quad$ [Online]. http://www.id.undp.org/content/indonesia/en/home/presscenter/articl es/2016/06/08/8-facts-about-indonesia-s-ocean.html. [Accessed 16 June 2017].

[5] D. Sutardi, "Mina Bahari," Dua Tahun Kerja Transformasi Perikanan: Mengelola Laut Untuk Masa Depan Bangsa, pp. 4-7, April 2017.

[6] A. Wibawa B.S., "Analisa Devinisi Kapal Ikan Purse Seini 109 GT KM. Surya Redjeki," Jurnal Ilmu Pengetahuan \& Teknologi Kelautan, vol. 7, no. 2, 2010 .

[7] S. Ardidja, Kapal Penangkap Ikan, Jakarta: Jurusan Teknologi Penagkapan Ikan Sekolah Tinggi Perikanan, 2007.

[8] E. Tupper, Introduction to Naval Architecture, 3rd Revised Reprint ed., Oxford: Elsevier Science Ltd., 2002.

[9] Nusantara, M. F., Akbar, S. R. \& Rachmadi, A., 2016. Analisa Metode Publish/subcribe untuk komunikasi data antar perangkat dalam lingkungan smarthome.

[10] Eclipse, 2013. Mosquitto. [Online] Available at: https://www.eclipse.org/proposals/technology.mosquitto/ [Accessed $3072018]$.

[11] Rochman, H. A., Primananda. R., Nurwasito. H, "Sistem Kendali Berbasis Mikrokontroler Menggunakan Protokol MQTT pada Smarthome" Vol. 1, No. 6, Juni2017, hlm. 445-455, Jurnal Pengembangan Teknlogi Informasi dan Ilmu Komputer (J-PTIIK) Universitas Brawijaya.

[12] http://www.mathworks.com/help/thingspeak/act-on-your-data.html 